\title{
Posterior reversible encephalopathy syndrome secondary to asymptomatic poststreptococcal glomerulonephritis in a child with sickle cell anemia: a case report
}

\author{
Ehab Hanafy ${ }^{1 *}$ D, Duaa Alshareef ${ }^{2}$, Suhaila Osman ${ }^{2}$, Abdullah Al Jabri' $^{2}$, Faisal Nazim ${ }^{1}$ and Gihan Mahmoud ${ }^{1}$
}

\begin{abstract}
Background: Posterior reversible encephalopathy syndrome is a neurotoxic condition that occurs as a result of the failure of posterior circulatory autoregulation in response to acute changes in blood pressure. Overperfusion with resultant disruption of the blood-brain barrier results in vasogenic edema, but not infarction. Posterior reversible encephalopathy syndrome can be the presenting feature of postinfectious glomerulonephritis, which has been reported in approximately $5 \%$ of hospitalized children, and it has been reported in very few cases of adult patients with sickle cell anemia. We report a very rare case of posterior reversible encephalopathy syndrome that occurred in a child with sickle cell anemia. This presentation should be differentiated from other neurologic manifestations that occur in patients with sickle cell anemia, because management is totally different.
\end{abstract}

Case presentation: We report what is to our knowledge the first reported case of a 9-year-old Saudi girl with sickle cell anemia who developed posterior reversible encephalopathy syndrome secondary to asymptomatic poststreptococcal glomerulonephritis. This occurred after full recovery from acute chest syndrome and severe vaso-occlusive crisis.

Conclusions: The purpose of this report is to emphasize that all efforts should be made to explore the causes of different neurologic manifestations that occur in patients with sickle cell anemia, because this will require different pathways of management.

Keywords: Sickle cell anemia, Posterior reversible encephalopathy syndrome, Stroke, Hypertension, Glomerulonephritis

\section{Background}

Stroke in sickle cell anemia (SCA) is a serious complication that occurs in various forms and needs to be managed promptly and effectively to prevent any irreversible neurologic deficit. This neurologic complication seen in children with SCA is different from a rare neurologic disorder known as posterior reversible encephalopathy syndrome (PRES), which is a clinicoradiological entity characterized by rapid onset of an altered level of consciousness, visual disturbance, headache, and seizures.

The exact pathophysiological mechanisms that could explain PRES are debatable; however, the most popular

\footnotetext{
*Correspondence: ehab.hmahmoud@gmail.com

${ }^{1}$ Prince Sultan Oncology Center, King Salman Armed Forces Hospital, Tabuk

100, Kingdom of Saudi Arabia

Full list of author information is available at the end of the article
}

one is related to increasing blood pressure causing failure of brain autoregulation. Uncontrolled hypertension leads to hyperperfusion and cerebral vessel damage, resulting in interstitial extravasation of proteins and fluids, causing vasogenic edema.

The other less popular theory postulates that PRES is due to vascular endothelial dysfunction that may occur as a result of systemic inflammatory conditions. This can be explained by the presence of a direct association of PRES with systemic inflammatory processes such as sepsis, eclampsia, transplant, and autoimmune disease [1]. We present a rare case of PRES in a child with SCA, and because it is a sort of neurologic insult, it should be cautiously differentiated from other neurologic manifestations that occur in SCA in which the management pathway is different. 


\section{Case presentation}

A 9-year-old Saudi girl was presented to our hospital with a fever of $38.5{ }^{\circ} \mathrm{C}$, cough, and shortness of breath. Her oxygen saturation was $88 \%$ on room air; her blood pressure was normal for her age $(110 / 75 \mathrm{mmHg})$; and she had no tachycardia ( 80 beats/minute). She had had abdominal pain for 2 days that was not responding to analgesics. She had been diagnosed with SCA at the age of 2 years. Both her parents are consanguineous and have the sickle cell trait, whereas all her siblings are sickle cell-negative on the basis of routine screening. The patient had no history of hypertension, diabetes, or other conditions of medical concern; no history of previous surgeries; and no history of drug allergies. Her developmental history was compatible with her age, and her vaccinations were up-to-date. She was followed regularly at our pediatric hematology clinic and receiving regular hydroxyurea and folic acid supplements.

On examination, the patient had no organomegaly; her ear, nose, and throat examination was unremarkable; and her initial neurologic examination was unremarkable with normal motor power, sensations, and reflexes. Subsequently, she was admitted to the hospital and diagnosed with acute chest syndrome on the basis of her clinical manifestations and bilateral lung infiltrates seen on chest $\mathrm{x}$-rays. Her concomitant abdominal pain was attributed to vaso-occlusive crisis. She was started on full supportive care, including antibiotics, analgesics, intravenous fluids, and oxygen supplementation, and she was given packed red blood cells once with minimal improvement. She underwent exchange transfusion because of progressive respiratory distress and increased oxygen requirement.

During her stay at the pediatric intensive care unit and after 5 days of exchange transfusion, the patient's respiratory distress and radiologic evidence of acute chest syndrome resolved; however, she developed systemic hypertension and was started on antihypertensive medications with slight improvement. Echocardiography showed mild mitral regurgitation with dilation of the left ventricle, and Doppler ultrasound showed patent hepatic and renal vasculature. The results of her blood workup were within normal ranges, apart from creatinine, which was slightly elevated (Table 1 ).

Four days later, the child had marked elevation of her blood pressure that was followed by seizures and sudden loss of vision. On examination, she was drowsy, had a Glasgow Coma Scale score of 10 on a scale of 15, and was responding to verbal stimuli. Her neurologic examination showed squinting of the right eye to the right side, and her pupils were equal and reactive to light. She was unable to recognize any objects. She had no signs of meningeal irritation, and results of her motor and sensory examinations were normal. Examination of her chest revealed that it was clear, and her liver was
Table 1 Results of blood workup at time of initial hypertensive episode

\begin{tabular}{lll}
\hline & Value & Normal range \\
\hline Sodium & 136 & $132-146 \mathrm{mmol} / \mathrm{L}$ \\
Potassium & 4.9 & $3.6-5.0 \mathrm{mmol} / \mathrm{L}$ \\
Chloride & 109 & $98-107 \mathrm{mmol} / \mathrm{L}$ \\
Enzymatic bicarbonate & 18 & $22-29 \mathrm{mmol} / \mathrm{L}$ \\
Urea nitrogen & 4.92 & $1.6-4.6 \mathrm{mmol} / \mathrm{L}$ \\
Creatinine & 109 & $20-70 \mu \mathrm{mol} / \mathrm{L}$ \\
Total protein & 65 & $64-86 \mathrm{~g} / \mathrm{L}$ \\
Albumin & 28 & $38-56 \mathrm{~g} / \mathrm{L}$ \\
ALP & 144 & $218-499 \mathrm{U} / \mathrm{L}$ \\
AST (SGOT) & 46 & $15-37 \mathrm{U} / \mathrm{L}$ \\
ALT (SGPT) & 37 & $24-49 \mathrm{U} / \mathrm{L}$ \\
Total bilirubin & 8 & $0-14 \mu \mathrm{mol} / \mathrm{L}$ \\
WBC & 21.98 & $5.0-13.0 \times 10^{3} / \mu l$ \\
Hemoglobin & 8.4 & $11.5-14 \mathrm{~g} / \mathrm{dl}$ \\
PLT & 113 & $180-400 \times 10^{3} / \mu \mathrm{l}$
\end{tabular}

Abbreviations: ALP Alkaline phosphatase, ALT Alanine aminotransferase, AST Aspartate aminotransferase, PLT Platelets, SGOT Serum glutamic-oxaloacetic transaminase, SGPT Serum glutamic-pyruvic transaminase, WBC White blood cell count

palpable $4 \mathrm{~cm}$ below the costal margin. Review of her other systems was unremarkable.

Urgent magnetic resonance imaging (MRI) of the patient's brain (Fig. 1) showed an ill-defined, nonenhanced area of abnormal hyperintense signaling on fluidattenuated inversion recovery (FLAIR) T2-weighted (T2W) images and isointensity on T1-weighted (T1W) images with restricted diffusion. A low apparent diffusion coefficient value was seen involving the cortex of the right occipitoparietal lobe and a tiny area of the same signal intensity within the right thalamic region suggestive of recent infarctions. The imaging studies also showed multiple ill-defined, nonenhanced patches of abnormal hyperintense signaling on FLAIR images, as well as isointense signaling on T1W images with no restriction of diffusion seen involving the cortex of the occipitoparietal region bilaterally, suggesting posterior reversible hypertensive encephalopathy. The patient's electroencephalogram was reported as normal. She was kept on full supportive measures, including antihypertensive and antiepileptic medications as well as antibiotics, in addition to intravenous fluids to improve renal function.

Further investigations were done to rule out a renal cause of hypertension. This included measurement of renin and aldosterone levels, which were normal. Her anti-streptolysin $\mathrm{O}$ titer was high at $490 \mathrm{IU} / \mathrm{ml}$ (normal range $0-200 \mathrm{IU} / \mathrm{ml}$ ), and her $\mathrm{C} 3$ level was significantly low at $0.22 \mathrm{~g} / \mathrm{L}$ (normal range $0.9-1.8 \mathrm{~g} / \mathrm{L}$ ). Urine analysis revealed 25-50 red blood cells (Table 2). 


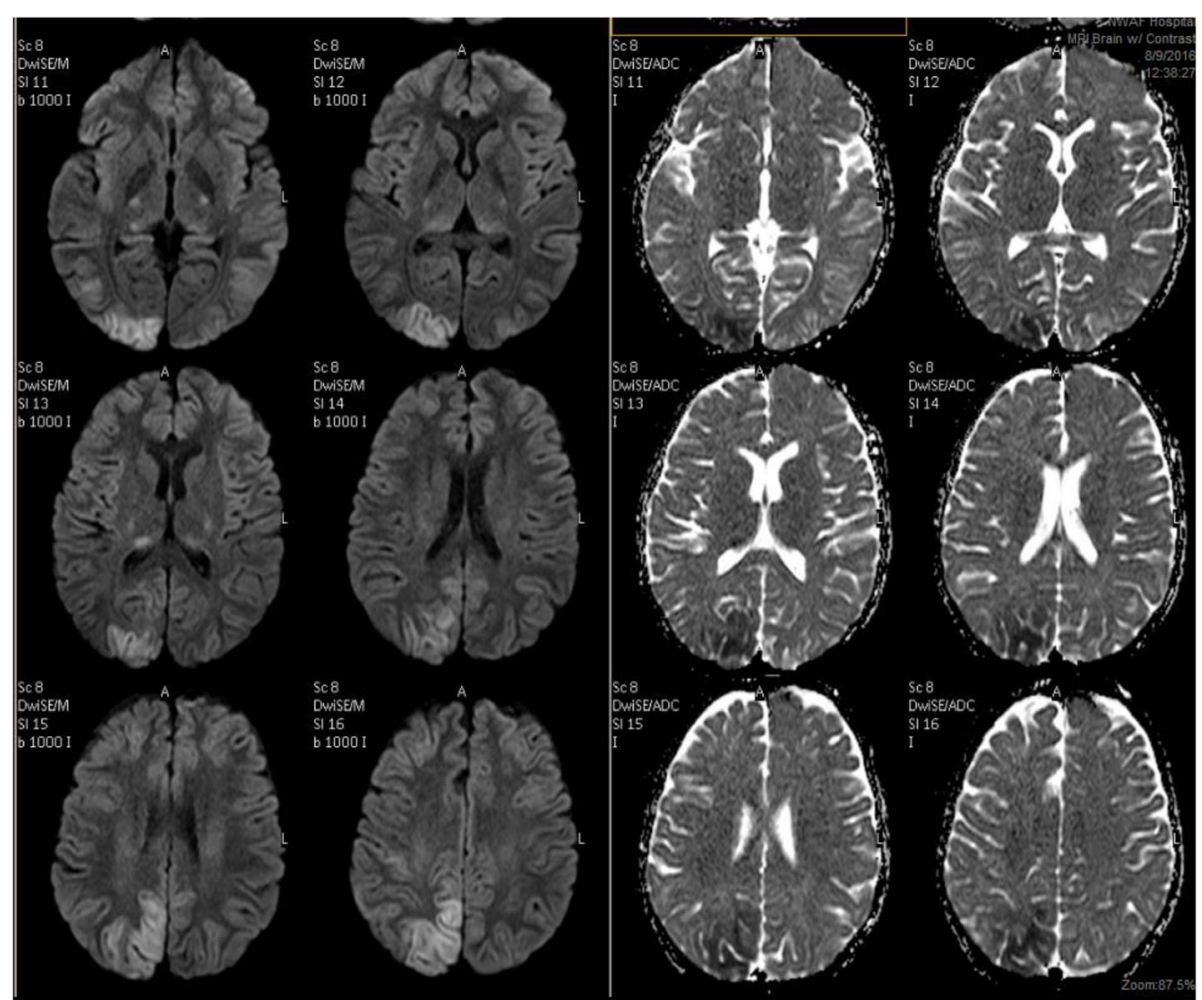

Fig. 1 Brain magnetic resonance imaging scans showing tiny areas of recent infarctions with a picture diagnostic of posterior reversible encephalopathy syndrome

The child started to improve gradually over a 1 -week period with full restoration of vision and adequate seizure control. Her general condition improved markedly, with an unremarkable systemic examination just within 10 days of her abrupt clinical deterioration.

Our impression was that our patient had PRES secondary to postinfectious glomerulonephritis. Recent brain infarctions can follow a severe attack of acute chest syndrome and vaso-occlusive crisis. Our patient is currently on a regular blood transfusion program as a secondary prevention of stroke. Brain MRI was repeated 2 months after presentation, and it showed that the previously mentioned scattered high T2W and high FLAIR signal intensity of the cortex and subcortical white matter with restricted diffusion were almost completely resolved. The results of repeat anti-streptolysin $\mathrm{O}$ titer, C3 level, and urine analysis were completely normal. Our patient is currently in good condition with no neurologic manifestations, and she attends regular monthly follow-up visits at our hematology clinic.

\section{Discussion}

We present a rare case of PRES in a child with SCA that was mostly secondary to glomerulonephritis. PRES as a neurologic condition should be interpreted carefully in
Table 2 Urine analysis

\begin{tabular}{lll}
\hline Analysis & Reference & Value \\
\hline SG & $1.010-1.025$ & 1.015 \\
$\mathrm{pH}$ & $6.0-7.0$ & 7.0 \\
Leukocyte & Negative & Negative \\
Nitrite & Negative & Negative \\
Protein & Negative & 30 mg/dl \\
Glucose & Negative & Negative \\
Ketone & Negative & Trace \\
Urobilinogen & $0.2-1$ mg/dl & 1.0 mg/dl \\
Bilirubin & Negative & Negative \\
Red blood cells & Negative & Large \\
Urine Appearance & & Bloody \\
Urine White blood cells & & Negative \\
Urine Red blood cells & & $25-50$ \\
Urine Bacteria & & Negative \\
Urine RBC casts & & $0-2$ \\
\hline
\end{tabular}

RBC Red blood cell, SG Specific gravity 
patients with SCA, because other neurologic conditions that occur in SCA have different pathways of management.

Blood pressure is generally lower than normal in patients with SCA. Those with higher levels (relative to this population) have an increased risk of stroke and death [2].

It has been shown that, compared with patients with SCA with lower blood pressure, patients with SCA and blood pressure values in the high range of normal have higher serum creatinine levels and an increased risk of pulmonary hypertension $[3,4]$. It is possible, though unproven, that moderate degrees of hypertension are more damaging to the kidney, particularly in patients with SCA compared with those without SCA. Therefore, it is our practice to treat these patients aggressively to avoid any possible renal impairment.

Hypertension is seen in only $2-6 \%$ of patients with SCA [5]. This has been attributed to several factors, including sodium and water wasting as a result of pathological involvement of the renal medulla, compensatory systemic vasodilation due to significant reductions in the microcirculation, and increased levels of serum prostaglandins and nitric oxide.

SCA can cause different renal syndromes and diseases that reflect the complex vasculopathy of SCA and the propensity of red blood cells to sickle in the renal medulla because of its hypoxic, acidotic, and hyperosmolar conditions. This includes glomerulopathies, chronic kidney disease, acute kidney injury, impaired urinary concentrating ability, hematuria, and other rare renal conditions. Renal involvement contributes substantially to the diminished life expectancy of patients with SCA, accounting for $16-18 \%$ of mortality [6].

It is of crucial importance to differentiate those renal conditions that occur as a result of vasculopathy in SCA and other renal diseases that are not related, because this will require pursuing a different management approach. Strokes in children and young adults with SCA continue to be a major cause of morbidity. Understanding the epidemiology and pathophysiology of overt strokes is critical to immediate and multidisciplinary team management. This was initially described in 1923 in a case of a child with SCA who had seizures and acute left hemiparesis [7]. In 1970, Powars et al. [8] described for the first time the high rate of overt ischemic strokes in children and young adults with SCA (6\%), as well as their high recurrence rates in the first 2 years after the initial event $(50 \%)$ and in the following 9 years poststroke (66\%). In 1990, investigators in the Cooperative Study of Sickle Cell Disease provided the most definitive and comprehensive study of the natural history of strokes across the life-span [9].
Children and adults with SCA have a high prevalence (4.01\%) and incidence (0.61 per 100 patient-years) of cerebrovascular accidents [9]. In patients with SCA, ischemic strokes were observed to have a bimodal distribution. They are more common in children and older adults. The lowest incidence was reported in adults aged 20-29 years. The risk factors associated with ischemic strokes include transient ischemic attack, low steadystate hemoglobin concentration, recent episode of acute chest syndrome, and elevated systolic blood pressure. In individuals with SCA, hemorrhagic stroke was most frequent in the 20- to 29-year-old age group. The associated risk factors included low steady-state hemoglobin and high leukocyte count [9].

PRES usually presents with rapid onset of symptoms, including headache, seizures, altered level of consciousness, and visual disturbance. The disorder should be associated with an acute episode of hypertension [10, 11].

Chronic kidney disease and acute kidney injury are both commonly present in patients with PRES [12]. The disorder is commonly associated with conditions that coexist in patients with renal disease, such as hypertension, vascular and autoimmune diseases, exposure to immunosuppressive drugs, and organ transplant.

PRES can be the presenting feature of postinfectious glomerulonephritis, which was reported in approximately $5 \%$ of hospitalized children. In these patients, hypertension is usually severe and is accompanied by headache, vomiting, depressed sensorium, confusion, visual disturbances, aphasia, memory loss, coma, and convulsions. The mechanism of hypertension is most likely retention of sodium and water with resulting expansion of the extracellular space [13].

Our patient had no suspected history of streptococcal infection or gross hematuria; however, the possibility of poststreptococcal glomerulonephritis in children with symptoms that may be secondary to hypertension even in the absence of gross hematuria or a history of a preceding streptococcal infection should always be considered.

PRES has been reported immediately after blood transfusion in a small number of patients. This is usually attributed to acute volume overloads by transfusion exceeding the capacity of autoregulation of perfusion pressure, resulting in vasogenic edema [14]. However, this was not reported after exchange transfusion.

The severity of clinical symptoms varies from one patient to another. The visual disturbance may present as blurring of vision, homonymous hemianopsia, or even cortical blindness [11]. Patients may be slightly confused or agitated or may become comatose [15]. Other symptoms that are less commonly seen include nausea, vomiting, and brain stem deficits $[11,15]$. Seizures and status epilepticus are common, and nonconvulsive status epilepticus may be more frequent than generalized status 
epilepticus [16]. Nonconvulsive status epilepticus should be suspected in patients with prolonged states of altered consciousness and may be mistaken for postictal confusion. Signs of nonconvulsive seizures may include stereotypic movements such as staring, eye blinking, or head turning. Postictal confusion usually lasts for hours. Both PRES and nonconvulsive status may persist for several days and may be mistaken for psychosis, drug intoxication, or psychogenic states [17].

PRES in adult patients with SCA has been reported in association with severe acute chest syndrome, recurrent priapism, sudden elevation of blood pressure, or renal failure. In all these instances, PRES was attributed to abrupt elevation in blood pressure or blood volume $[18,19]$.

The pathophysiology of PRES remains controversial. The two main hypotheses contradict each other. One involves impaired cerebral autoregulation with subsequent increase in cerebral blood flow, whereas the other theory involves endothelial dysfunction with cerebral hypoperfusion. This hypoperfusion hypothesis is more applicable in cases of PRES associated with cytotoxic therapy. In both hypotheses, cerebral blood perfusion abnormalities are related to blood-brain barrier dysfunction with cerebral vasogenic edema [20].

The most characteristic imaging pattern in PRES is the presence of edema involving the white matter of the posterior portions of both cerebral hemispheres, especially in the parieto-occipital regions. This is usually reported in a relatively symmetric pattern with sparing of the calcarine and paramedian parts of the occipital lobes [15]. However, other structures (such as the brain stem, cerebellum, and frontal and temporal lobes) may also be involved. The abnormality affects primarily the subcortical white matter; yet, the cortex and the basal ganglia may also be involved [21]. Gyriform signal enhancements are rare. Furthermore, parenchymal hemorrhage can occur in complicated cases.

In many cases, distinguishing acute cerebral infarcts from PRES is still challenging [22]. MRI is the imaging modality of choice, and although both PRES and cerebral infarcts present with abnormal hyperintensities on fluid-sensitive sequences, the distribution of signal abnormalities is usually different in both disorders. Diffusion-weighted imaging (DWI) typically is positive in cerebral infarcts, whereas DWI in PRES may or may not be positive [23, 24]. Performing diffusion-weighted MRI of the brain is important to rule out the diagnosis of PRES.

No clinical trials have evaluated the management of PRES, but rapid withdrawal of the trigger factor appears to improve the rate of recovery and avoids possible complications. The prognosis is good because complete reversal of clinical symptoms usually occurs within a few days. Delay in diagnosis and treatment may lead to serious and permanent neurologic sequelae. Therefore, increased awareness of PRES is of crucial importance for the pediatrician.

\section{Conclusions}

Unlike stroke, PRES per se is not an indication for a blood transfusion program in patients with SCA. However, when neurologic symptoms occur, further investigations should be carried out to verify whether these neurologic manifestations are directly related to SCA or whether other pathology is involved, because this will call for extremely different management pathways.

\section{Abbreviations \\ ALP: Alkaline phosphatase; ALT: Alanine aminotransferase; AST: Aspartate aminotransferase; DWI: Diffusion-weighted imaging; FLAIR: Fluid-attenuated inversion recovery; MRI: Magnetic resonance imaging; PLT: Platelets; \\ PRES: Posterior reversible encephalopathy syndrome; RBC: Red blood cells; SCA: Sickle cell anemia; SG: Specific gravity; SGOT: Serum glutamic-oxaloacetic transaminase; SGPT: Serum glutamic-pyruvic transaminase; T1W: T1-weighted; T2W: T2-weighted; WBC: White blood cell count}

\section{Acknowledgements}

Not applicable.

\section{Funding}

The authors received no financial support for the research, authorship, and/or publication of this article.

\section{Availability of data and materials}

Not applicable.

\section{Authors' contributions}

EH made substantial contributions to conception and design, acquisition of the data, drafting of the manuscript, and revising the manuscript critically for important intellectual content. DA contributed by acquiring the data and drafting the manuscript. SO contributed by acquiring the data and revising the manuscript. AAJ revised the manuscript critically for important intellectual content. FN contributed by acquiring the data and revising the manuscript. GM revised the manuscript critically for important intellectual content. All authors read and approved the final manuscript.

Ethics approval and consent to participate Not applicable.

\section{Consent for publication}

Written informed consent was obtained from the patient's legal guardian for publication of this case report and any accompanying images. A copy of the written consent is available for review by the Editor-in-Chief of this journal.

\section{Competing interests}

The authors declare that they have no competing interests.

\section{Publisher's Note}

Springer Nature remains neutral with regard to jurisdictional claims in published maps and institutional affiliations.

\section{Author details}

${ }^{1}$ Prince Sultan Oncology Center, King Salman Armed Forces Hospital, Tabuk 100, Kingdom of Saudi Arabia. ${ }^{2}$ Pediatric Department, King Salman Armed Forces Hospital, Tabuk, Kingdom of Saudi Arabia. 
Received: 1 September 2017 Accepted: 27 December 2017

Published online: 01 February 2018

\section{References}

1. Hobson EV, Craven I, Blank SC. Posterior reversible encephalopathy syndrome: a truly treatable neurologic illness. Perit Dial Int. 2012;32(6):590-4. doi:https://doi.org/10.3747/pdi.2012.00152

2. Pegelow CH, Colangelo L, Steinberg M, Wright EC, Smith J, Phillips G, Vichinsky E. Natural history of blood pressure in sickle cell disease: risks for stroke and death associated with relative hypertension in sickle cell anemia. Am J Med. 1997;102(2):171-7.

3. Gordeuk VR, Sachdev V, Taylor JG, Gladwin MT, Kato G, Castro O. Relative systemic hypertension in patients with sickle cell disease is associated with risk of pulmonary hypertension and renal insufficiency. Am J Hematol. 2008;83(1):15-8.

4. Thompson J, Reid M, Hambleton I, Serjeant GR. Albuminuria and renal function in homozygous sickle cell disease: observations from a cohort study. Arch Intern Med. 2007;167(7):701-8.

5. Hatch FE, Crowe LR, Miles DE, Young JP, Portner ME. Altered vascular reactivity in sickle hemoglobinopathy: a possible protective factor from hypertension. Am J Hypertens. 1989;2(1):2-8.

6. Nath KA, Hebbel RP. Sickle cell disease: renal manifestations and mechanisms. Nat Rev Nephrol. 2015;11(3):161-71. doi:https://doi.org/10.1038/nrneph.2015.8.

7. Sydentricked VP, Mulherin WA, Houseal RW. Sickle cell anemia: report of two cases in children with necropsy in one case. Am J Dis Child. 1923:26(2):132-54

8. Powars D, Wilson B, Imbus C, Pegelow C, Allen J. The natural history of stroke in sickle cell disease. Am J Med. 1978;65(3):461-71.

9. Ohene-Frempong K, Weiner SJ, Sleeper LA, et al. Cerebrovascular accidents in sickle cell disease: rates and risk factors. Blood. 1998;91(1):288-94.

10. McKinney AM, Short J, Truwit CL, McKinney ZJ, Kozak OS, SantaCruz KS, et al. Posterior reversible encephalopathy syndrome: incidence of atypical regions of involvement and imaging findings. AJR Am J Roentgenol. 2007;189(4):904-12.

11. Roth C, Ferbert A. The posterior reversible encephalopathy syndrome: what's certain, what's new? Pract Neurol. 2011;11(3):136-44

12. Fugate JE, Claassen DO, Cloft HJ, Kallmes DF, Kozak OS, Rabinstein AA Posterior reversible encephalopathy syndrome: associated clinical and radiologic findings. Mayo Clin Proc. 2010;85(5):427-32.

13. Burke EC, Titus JL. Post-streptococcal acute glomerulonephritis in children. Med Clin North Am. 1966:50(4):1141-58

14. Wada K, Kano M, Machida Y, Hattori N, Miwa H. Posterior reversible encephalopathy syndrome induced after blood transfusion for severe anemia. Case Rep Clin Med. 2013;2(5):332-4. doi:https://doi.org/10.4236/ crcm.2013.25089.

15. Hinchey J, Chaves C, Appignani B, Breen J, Pao L, Wang A, et al. A reversible posterior leukoencephalopathy syndrome. N Engl J Med. 1996;334:494-500.

16. Kozak OS, Wijdicks EF, Manno EM, Miley JT, Rabinstein AA. Status epilepticus as initial manifestation of posterior reversible encephalopathy syndrome. Neurology. 2007;69(9):894-7.

17. Kaplan PW. No, some types of nonconvulsive status epilepticus cause little permanent neurologic sequelae (or: "the cure may be worse than the disease"). Neurophysiol Clin. 2000;30(6):377-82.

18. Henderson JN, Noetzel MJ, McKinstry RC, White DA, Armstrong M, DeBaun MR. Reversible posterior leukoencephalopathy syndrome and silent cerebral infarcts are associated with severe acute chest syndrome in children with sickle cell disease. Blood. 2003;101(2):415-9.

19. Frye RE. Reversible posterior leukoencephalopathy syndrome in sickle cell anemia. Pediatr Neurol. 2009;40(4):298-301.

20. Bartynski WS. Posterior reversible encephalopathy syndrome, part 2: controversies surrounding pathophysiology of vasogenic edema. AJNR Am J Neuroradiol. 2008:29(6):1043-9.

21. Lamy C, Oppenheim C, Meder JF, Mas JL. Neuroimaging in posterior reversible encephalopathy syndrome. J Neuroimaging. 2004;14(2):89-96.
22. Donmez FY, Guleryuz P, Agildere M. MRI findings in childhood PRES: what is different than the adults? Clin Neuroradiol. 2016:26(2):209-13. doi:https://doi.org/10.1007/s00062-014-0350-2

23. Mukherjee P, McKinstry RC. Reversible posterior leukoencephalopathy syndrome: evaluation with diffusion-tensor MR imaging. Radiology. 2001;219(3):756-65.

24. Provenzale JM, Engelter ST, Petrella JR, Smith JS, MacFall JR. Use of MR exponential diffusion-weighted images to eradicate T2 "shine-through" effect. AJR Am J Roentgenol. 1999;172(2):537-9.

\section{Submit your next manuscript to BioMed Central and we will help you at every step:}

- We accept pre-submission inquiries

- Our selector tool helps you to find the most relevant journal

- We provide round the clock customer support

- Convenient online submission

- Thorough peer review

- Inclusion in PubMed and all major indexing services

- Maximum visibility for your research

Submit your manuscript at www.biomedcentral.com/submit 